\title{
Studying the Effect of Light Incidence Angle on Photoelectric Parameters of Solar Cells by Simulation
}

\author{
Jasurbek Gulomov*, Rayimjon Aliev, Avazbek Mirzaalimov, Navruzbek Mirzaalimov, \\ Jamshidbek Kakhkhorov, Bobur Rashidov, Sodikjon Temirov
}

Department of Physics, Faculty of Physics and Mathematics, Andijan State University, Andijan, Uzbekistan

\begin{abstract}
It is crucial to examine the dependence of photoelectric parameters of solar cells on the light incidence angle. In the present study, two solar cell models have been developed using the Sentaurus Technology Computer-Aided Design software package. The light spectrum AM1.5 has been directed on the frontal surface of solar cells at different angles. It has been found that the angular coefficient of the photoelectric parameters of a solar cell with nanoparticles included, is two times more than that of a simple solar cell. Besides, it has been found that the efficiency of platinum nanoparticles induced solar cells is 2.15 times greater than simple solar cell efficiency. When the light incidence angle has been varied from 0 to 60 degrees, the short-circuit current has changed by $11 \%$ for simple solar cells and by $10 \%$ for solar cells with nanoparticles. Further, it has been observed that the variation of power for simple solar cells is $12.5 \%$, while it is $10.5 \%$ for solar cells with nanoparticles. In addition, the short-circuit current of solar cells with nanoparticles has been found to be linear within a light incidence angle ranging from 0 to 60 degrees.
\end{abstract}

Keywords: solar cell, modelling, nanowire, I-V characteristics, basic photoelectric parameters

Article History: Received: 30th January 2021; Revised: $15^{\text {th }}$ March 2021; Accepted: 20 th April 2021; Available online: 28 th April 2021

How to Cite This Article: Gulomov, J., Aliev, R., Mirzaalimov, A., Mirzaalimov, N., Kakhkhorov, J., Rashidov, B., Temirov, S.(2021) Studying the Effect of Light Incidence Angle on Photoelectric Parameters of Solar Cells by Simulation. Int. Journal of Renewable Energy Development, 10(4), 731-736.

https://doi.org/10.14710/ijred.2021.36277

\section{Introduction}

Today, the use of various renewable energy resources in order to better the environment is a critical issue. The types of renewable energy sources have increased in recent years (Benli 2013). Converting solar energy into electricity is one of the most productive ways of harnessing renewable energy resources. Accordingly, recent efforts have focussed on increasing the efficiency and decreasing the cost of semiconductor solar cells (Solanki and Singh 2017). Silicon-based solar cells constitute $97 \%$ of the solar cells produced in the industry, as silicon is the most common semiconductor material on the Earth (Saga 2010). There are high-efficiency solar cells based on other semiconductors, but most of them are expensive. Therefore, studying silicon-based solar cells is important.

There are three types of energy losses in solar cells: optical, recombination, and thermal. These losses limit the theoretical maximum efficiency of solar cells. In case of silicon solar cells, these losses do not exceed 29\% (Shockley and Queisser 1961). Methods for creating surface textures (Kumaravelu et al. 2002) and coating with optical layers (Gulomov et al. 2020) have been developed to improve the optical properties of silicon solar cells. The front and back sides of the solar cell need to be covered with optical layers to reduce surface recombination (Aliev, Abduvoxidov, Mirzaalimov, Gulomov 2020). Also, making rear contacts in the form of a grid in order to improve thermal conductivity and protect the cell from self-heating, is recommended. When a nanoparticle is inserted into silicon, it affects the properties of solar cells (Atwater and Polman 2010, Klimov 2009, Schuller et al. 2010). The light incidence angle changes according to the position of the sun (Seshan 2010). Therefore, in this paper, the dependence of basic photoelectric parameters of silicon solar cells on the AOI (Angle of Incidence) has been studied.

Currently, nano-engineering has a deep impact on almost all spheres of life. The latest scientific research shows that the laws of nanotechnology physics are unlike those of classical physics. In order to better understand this phenomenon, it is necessary to reckon that a change in the size of crystals affects each physical process. For example, in classical physics the melting point of a crystal is constant. But in the case of nanoscale crystals, the melting temperature changes according to the size of the crystal. Here, the decrease in the number of atoms reduces the gravitational and coulomb forces among atoms. It is well known that, surface plasmon resonance induced by Nobel metallic nanoparticles leads to an increase in an absorption coefficient of dye in dye-sensitized solar cells. The effect has been theoretically described as an increase of local electromagnetic field nearby metal Surfaces which is found when wavelengths of irradiation sources are correlated with the optical absorption of the surface

* Corresponding author: jasurbekgulomov@yahoo.com 
plasmon resonance. The modification of the surfaces for an enhancement of optical absorption, hence, provides a good method to improve efficiency of an optoelectronic device involving photon absorption. Moreover, using metal nanoparticle, the magnitude of Raman scattering is increased. These scattering provides more photons which will be available to excite surface plasmons as a result electrons to be excited and travel through the thin film SC to creat a current. In reference (Sarkar et al. 2018), the effect of nanoparticle dimension, for enhancement of extinction in terms of absorption and scattering by means of surface plasmon, was investigated. In previous research, the effects of gold, silver, copper, and platinum nanoparticles on silicon-based solar cells have been investigated (Aliev et al. 2020). If the effect of nanoplasmonics on silicon solar cells is analyzed, it may be possible to determine whether nanoparticles can increase or decrease the efficiency of solar cells. Therefore, this study provides detailed information about nanoparticles to be introduced into crystalline silicon solar cells, with regard to their type and size and arrangements consisting of differing distances among neighbouring nanoparticles.

Given the above context, this study examines the I-V characteristics of silicon solar cells and definitions of related basic photoelectric parameters. The AOI on solar cells and panels is determined experimentally using a new special (tracer) machine. First, the location of the sun is determined by the time and coordinates. Second, the AOI is calculated based on the location of the sun.

Coming to the methodology of the study, it is notable that several different methods of digital modeling have been designed in order to study silicon solar cells. Currently, the programs which are most reliable and most widely used by scientists include Silvaco TCAD (Technology Computing Aided Design) and Synopsys Sentaurus TCAD (Gulomov, Aliev, Nasirov, and Ziyoitdinov 2020). These programs are created for highprecision modeling of semiconductor devices in 3D / 2D / 1D format (Burgelman et al. 2000). However, Comsol Multiphysics is used to model the interaction between the solar cells and the environment.

A further point to be noted with regard to this study is that, as part of the latest research, the optical parameters of amorphous silicon solar cells which contained silver nanoparticles in their optical layer, were studied as a function of the AOI. Here, the dependence of the absorption coefficient of the amorphous silicon solar cell on the AOI was improved to $6 \%$. Besides, several scientists have studied nanoparticles inserted into the frontal optical layer of the solar cells, and the resultant effect of surface plasmons on solar cells (Yang et al. 2011). In this context, the present study focuses on investigating the AOI dependencies of the main photoelectric parameters of the silicon solar cells which had platinum nanoparticles inserted into the $\mathrm{n}$ region. The reason for the choice of platinum material as a nanoparticle is justified by previous scientific research which shows that the effect of platinum on the solar cell is greater than that of other types of nanoparticles (Aliev et al. 2020). Therefore, the authors of the present work have researched the dependence of the main photoelectric parameters of nanoparticles induced solar cell (NISC) and simple solar cell (SSC) on the AOI.

\section{Materials and Methods}

\subsection{Simulation method}

For modeling solar cells, Synopsys's Sentaurus TCAD software has been used. The Sentaurus TCAD consists of 20 instruments, of which 17 are primary and 3 are auxiliary instruments. Four main tools are used for modeling solar cells: Sentaurus Structure Editor (SDE), Sentaurus Device (SDevice), Sentaurus Visual (SVisual), and Sentaurus Work Bench (SWB). To create geometric models of solar cells, independent instrument SDE has been used. These geometric models have been created by the writing of codes, using Tool Command Language (TCL) (Sentaurus Structure Editor User Guide 2018). If the user does not know how to use this program, it is also possible to draw a geometric model using shapes.

SDevice is a multi-dimensional high-level device simulator. SDevice is used to simulate the electrical, thermal and optical properties of semiconductor devices. Semiconductor devices are simulated by numerical methods in SDevice. Current density, voltage and charge are calculated based on physical equations, distribution, and conduction mechanisms of minority charge carriers (Sentaurus Device User Guide 2018). Using SVisual, calculation results are visualized in one, two, and three dimensions and different graphs are generated. SVisual helps view the I-V characteristics of silicon solar cells graphically and generates graphics for articles or presentations (Sentaurus Visual User Guide 2018).

Table 1

Information regarding each area of the geometric models of NISC and SSC

\begin{tabular}{|c|c|c|c|c|c|c|c|c|}
\hline & & 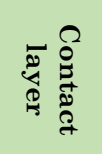 & 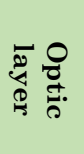 & 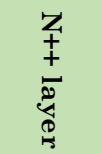 & 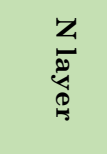 & 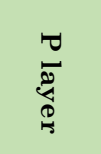 & 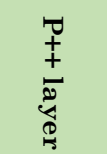 & $\begin{array}{l}Z \\
\text { Z } \\
0 \\
0 \\
\vdots \\
\vdots \\
0\end{array}$ \\
\hline \multirow{5}{*}{ NISC } & Material type & $\mathrm{Si}$ & $\mathrm{SiO}_{2}$ & $\mathrm{Si}$ & $\mathrm{Si}$ & $\mathrm{Si}$ & $\mathrm{Si}$ & $\mathrm{Pt}$ \\
\hline & Thickness, $\mu \mathrm{m}$ & $3 r$ & $3 r$ & $5 \mathrm{r}$ & $7 \mathrm{r}$ & $46 r$ & $4 \mathrm{r}$ & $2 \mathrm{r}$ \\
\hline & Width, $\mu \mathrm{m}$ & 0.2 & 1.8 & 2 & 2 & 2 & 2 & $2 \mathrm{r}$ \\
\hline & Doping atoms type & $\mathrm{P}$ & - & $\mathrm{P}$ & $\mathrm{P}$ & $\mathrm{B}$ & $\mathrm{B}$ & \\
\hline & Doping concentration, $\mathrm{cm}^{-3}$ & $1 \times 10^{19}$ & - & $1 \times 10^{18}$ & $1 \times 10^{17}$ & $1 \times 10^{15}$ & $1 \times 10^{16}$ & \\
\hline \multirow{5}{*}{ SSC } & Material type & $\mathrm{Si}$ & $\mathrm{SiO}_{2}$ & $\mathrm{Si}$ & $\mathrm{Si}$ & $\mathrm{Si}$ & $\mathrm{Si}$ & - \\
\hline & Thickness, $\mu \mathrm{m}$ & $3 r$ & $3 r$ & $5 \mathrm{r}$ & $7 \mathrm{r}$ & $46 \mathrm{r}$ & $4 \mathrm{r}$ & \\
\hline & Width, $\mu \mathrm{m}$ & 0.2 & 1.8 & 2 & 2 & 2 & 2 & \\
\hline & Doping atoms type & $\mathrm{P}$ & - & $\mathrm{P}$ & $\mathrm{P}$ & B & $\mathrm{B}$ & \\
\hline & Doping concentration, $\mathrm{cm}^{-3}$ & $1 \times 10^{19}$ & - & $1 \times 10^{18}$ & $1 \times 10^{17}$ & $1 \times 10^{15}$ & $1 \times 10^{16}$ & \\
\hline
\end{tabular}


a)

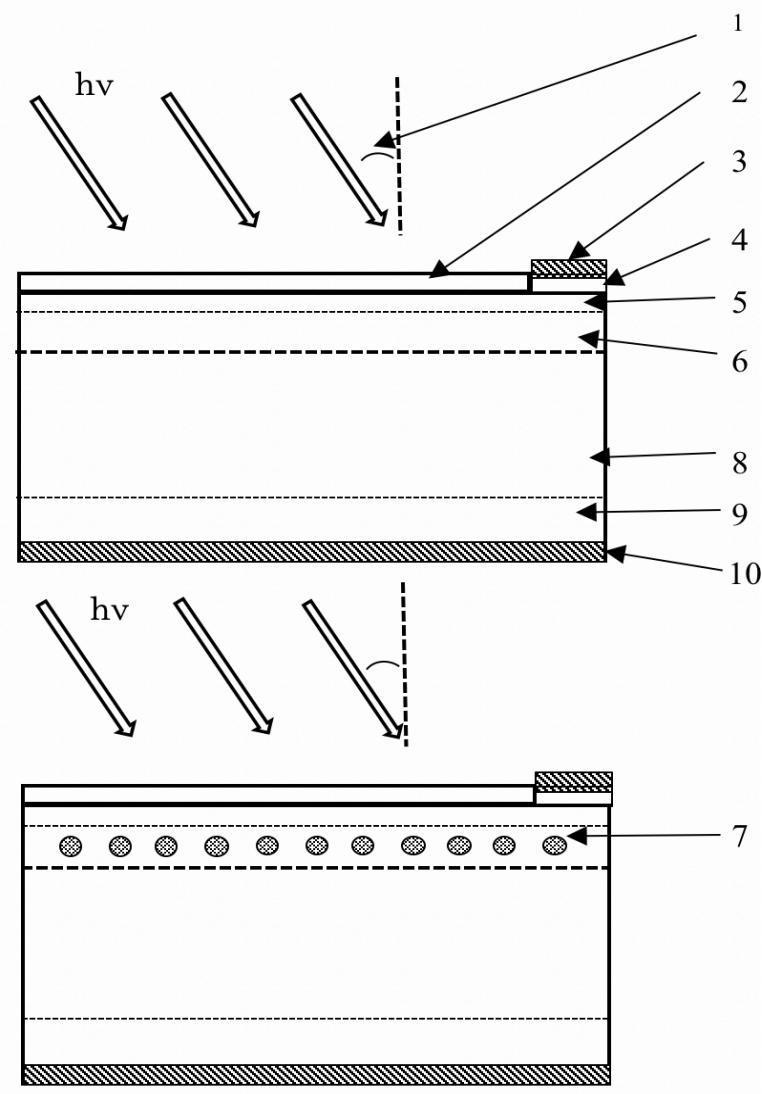

Fig. 1 Schematic diagram of solar cells: a - SSC, b - NISC. 1 - the angle of incidence of light, 2 - optic layer, 3 - front contact, 4 - contact layer, $5-\mathrm{n}++$ layer, 6 - n layer, 7 -nanowire, 8 - p layer, 9 - p++ layer, and 10 - back contact.

The SWB framework enables all instruments to work simultaneously (in one environment). This environment is executed by SWB, which has wide possibilities of solving various problems. Here, it is possible to obtain results for several different values of the model at the same time. Another advantage of SWB is the possibility of giving values to the variables introduced in SDevice and SDE files (Sentaurus Workbench User Guide 2018).

\subsection{Geometric method}

The geometric model of solar cells is formed in the following order.

1. The coordinates, names, and material types of the fields are given.

2. Doping concentration and doping type are given.

3. Electrodes are given and activated.

4. All regions are meshed. The $\mathrm{p}-\mathrm{n}$ junction and nanoparticles regions should be meshed smaller than other regions for better and faster calculations.

Geometric models of SSC and NISC have been created. The dimensions of the NISC are proportional to the radius (r) of the nanoparticles: the optical layer thickness is $3 \mathrm{r}$, the $\mathrm{n}++$ layer thickness is $5 \mathrm{r}$, the $\mathrm{n}$ layer thickness is $7 \mathrm{r}$, the $\mathrm{p}$ layer thickness is $45 \mathrm{r}$, and the $\mathrm{p}++$ layer thickness is $5 \mathrm{r}$. The width of the solar cell model is $2 \mu \mathrm{m}$ (Table 1 ). Platinum, gold, copper, and silver materials were selected as nanoparticles.

\subsection{Theory}

The reflection and transmission coefficients of the surfaces are calculated using the AOI and refractive indices of media. Here, the Fresnel coefficients method is chiefly used. Fresnel coefficients are calculated using equations (1), (2), (3) and (4) (Gulomov et al. 2020).

$r_{\perp}=\frac{n_{1} \cos \beta-n_{2} \cos \gamma}{n_{1} \cos \beta+n_{2} \cos \gamma}$

$t_{\perp}=\frac{2 n_{1} \cos \beta}{n_{1} \cos \beta+n_{2} \cos \gamma}$

$r_{\|}=\frac{n_{1} \cos \gamma-n_{2} \cos \beta}{n_{1} \cos \gamma+n_{2} \cos \beta}$

$t_{\|}=\frac{2 n_{1} \cos \beta}{n_{1} \cos \gamma+n_{2} \cos \beta}$

Where: $\mathrm{n}_{1}$ - refractive index of the first media, $\mathrm{n}_{2}-$ refractive index of the second media, $B-\mathrm{AOI}_{\mathrm{Y}}-$ refraction angle light.

The reflection and transmission coefficients of the surfaces are determined by using the Fresnel coefficients as shown in equations (5) and (6).

$$
\begin{aligned}
& R=\frac{\left(r^{\|}\right)^{2}+\left(r^{\perp}\right)^{2}}{2} \\
& T=\frac{n_{1} \cos \gamma}{n_{0} \cos \beta} \cdot \frac{1}{t}
\end{aligned}
$$

Where: $\mathrm{R}$ - Reflection, $\mathrm{T}$ - Transmission 
The Burger-Lambert law is used to determine the light absorption in the semiconductor layers, as shown in equation (7).

$$
I=I_{0} e^{-a d}
$$

Where: $d$ - thickness of the layer, $\alpha$ - absorption coefficient of layer, $\mathrm{I}_{0}$ - the initial intensity of light, I -the light intensity, which is the end of d layer.

Fresnel formulas alone are used to determine the optical properties of surfaces. The Burger-Lambert law alone is used to calculate the absorption in a layer. However, solar cells are multilayer semiconductor devices. In equation (12), the Fresnel and Burger-Lambert laws can be applied simultaneously by using the Transfer Matrix Method (TMM) (Gulomov et al. 2020).

$$
\begin{aligned}
& \frac{1}{t_{01}}\left[\begin{array}{cc}
1 & r_{01} \\
r_{01} & 1
\end{array}\right] \equiv D_{01} \\
& {\left[\begin{array}{cc}
e^{i k d} & 0 \\
0 & e^{-i k d}
\end{array}\right] \equiv P_{1}} \\
& {\left[\begin{array}{c}
E_{i} \\
E_{2}
\end{array}\right]=D_{01} \cdot P_{1} \cdot D_{12} \cdot P_{2} \cdot D_{23}\left[\begin{array}{c}
E_{t} \\
0
\end{array}\right]} \\
& D_{01} \cdot P_{1} \cdot D_{12} \cdot P_{2} \cdot D_{23} \equiv M \\
& {\left[\begin{array}{c}
E_{i} \\
E_{2}
\end{array}\right]=M\left[\begin{array}{c}
E_{t} \\
0
\end{array}\right]}
\end{aligned}
$$

Where: $\mathrm{D}_{\mathrm{ij}}$ - transmission matrix, $\mathrm{P}_{\mathrm{j}}$ - propagation matrix, $\mathrm{M}$ - transfer matrix, $\mathrm{E}_{\mathrm{i}}$ - the electric field of the incident light, $\mathrm{E}_{\mathrm{r}}$ - the electric field of the reflected light, $\mathrm{E}_{\mathrm{t}}-$ the electric field of the transmitted light, $r_{\mathrm{ij}}$, and $t_{\mathrm{ij}}-$ Fresnel coefficient.

TMM helps to analyze the optical properties of solar cells. The optical phenomena of the interface between nanoparticles and semiconductors can be explained by using this method. However, the physical phenomena in nanoparticles cannot be explained only by optics. The electrons inside the nanoparticle vibrate in the electromagnetic field of light. Nanoparticles absorb light in one spectrum and emit light in another. This phenomenon is known as the nanoplasmonic effect.

The nanoplasmonic effect can cause three phenomena:

1. The nanoparticle absorbs light in one spectrum and emits light in another.

2. If the oscillation frequency of the electromagnetic field of the light source is equal to the oscillation frequency of the electrons inside the nanoparticle, the resonance phenomenon occurs. Subsequently, the nanoparticle emits extra electrons.

3. Both the above events can occur simultaneously.

The appearance of the nanoplasmonic effect depends directly on the size of the nanoparticle and its material type (Sonnichsen 2001).

$$
\begin{aligned}
& I_{s c a}(\omega)=\frac{I_{0}(\omega)}{S} C_{s c a}(\omega) \\
& \alpha=3 \varepsilon_{0} V \frac{\varepsilon_{r}-1}{\varepsilon_{r}+2} \\
& \varepsilon_{r}=\varepsilon_{r}^{\prime}+i \varepsilon_{r}^{\prime \prime} \\
& \mathrm{C}_{s c a}=\frac{k^{4}}{6 \pi}\left|\frac{\alpha}{\varepsilon_{0}}\right|^{2}
\end{aligned}
$$

Where: $\mathrm{I}_{0}$-intensity, which is the incidence to the nanoparticle, $\mathrm{I}_{\mathrm{sca}}$ - light intensity, nanoparticle radiate, $\alpha$ - absorption coefficient, V - the volume of the nanoparticle, $\omega-$ light frequency, $\varepsilon_{\mathrm{r}}-$ relative permittivity, $\mathrm{k}$ - wavenumber.

Equation (13) was used to determine the relationship between the light intensity which is incident on a nanoparticle and the light intensity which is emitted by the nanoparticle.

\section{Results}

Figure 2 shows the dependence of the open-circuit voltage of an SSC and NISC on the AOI. The quality of the curves of the open-circuit voltage for both the NISC and $\mathrm{SSC}$ is approximately the same. However, the open-circuit voltage of the NISC is $0.02 \mathrm{~V}$ higher than that of the SSC.

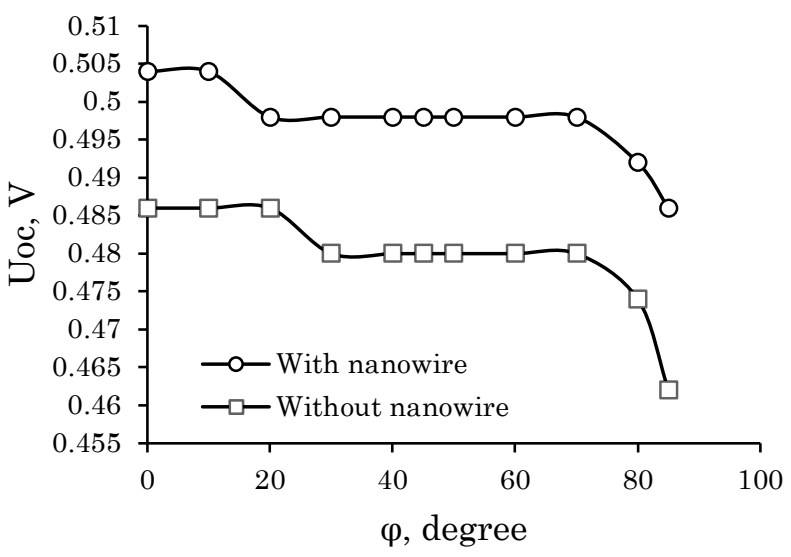

Fig. 2. The dependence of the open-circuit voltage of an SSC and an NISC on the AOI.

Analogous quality dependencies of the other main photoelectric parameters on the AOI are observed for both types of solar cells: short-circuit current density, maximum power density and fill factor.

In Figure 3, the short circuit current density of the NISC is two times greater than that of the SSC. However, the quality of both curves is the same. The linearity of the curve for the NISC is better than that of the SSC. In Figure 4, the power density curve is similar to the shortcircuit density curve for both types of solar cells.

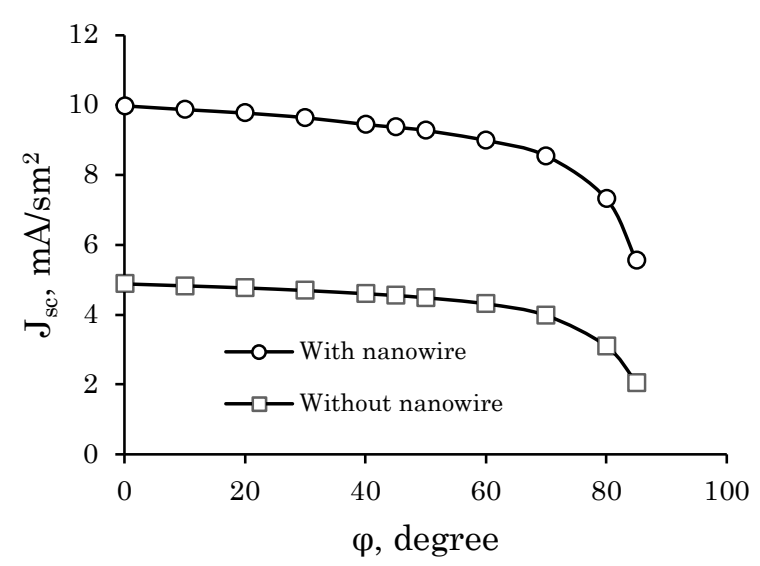

Fig. 3. The dependence of the short-circuit current density of an SSC and an NISC on AOI. 


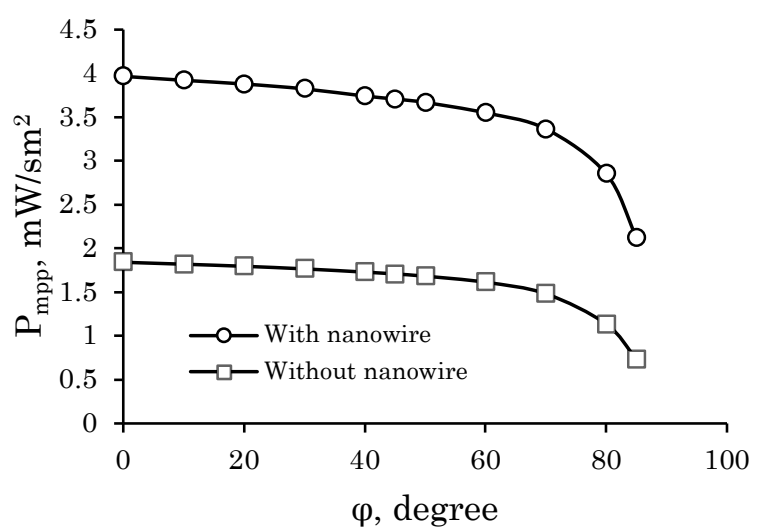

Fig. 4. The dependence of maximum power of an SSC and an NISC on the AOI.

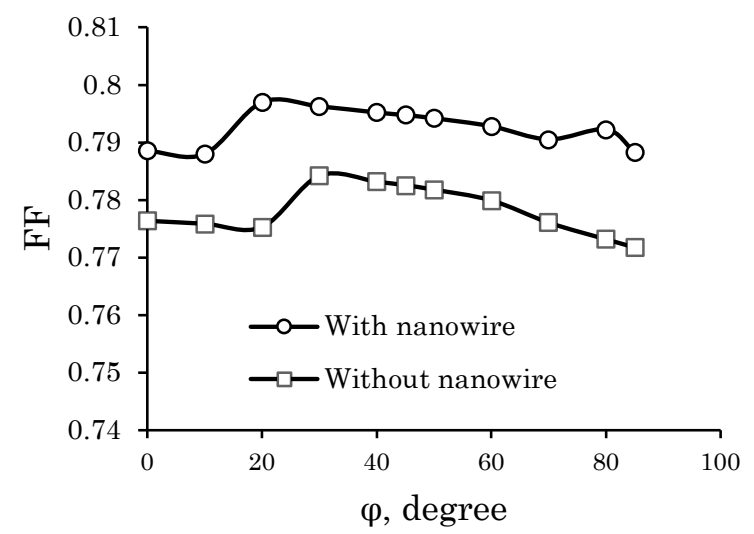

Fig. 5. The dependence of the fill factor of an SSC and an NISC on AOI.

In Figure 5, the dependence of the fill factor on AOI is not linear for both types of solar cells. The fill factor relating to I-V characteristics of solar cells changes at different AOI. However, the curves showing the quality of dependence of fill factor on AOI, for both NISC and SSC are the same.

\section{Discussion}

Received results show that the angular coefficients of the photoelectric parameters, at different AOIs, have different values. Angular coefficients of short- circuit current and power density are calculated for the linear part of the curves. In Figure 3, the angular coefficient of short-circuit current density is $\mathrm{d} J_{\mathrm{sc}} / \mathrm{d} \varphi=0.021 \mathrm{~mA} / \mathrm{sm}^{2}$ degree, within the angular range of AOI from 0 to 70 degrees, for NISC. In Figure 4, the angular coefficient of power density is $\mathrm{dP} / \mathrm{d} \varphi=8.6 \times 10^{-3} \mathrm{~mW} / \mathrm{sm}^{2}$ degree for NISC. These coefficients are $\mathrm{dJ}_{\mathrm{sc}} / \mathrm{d} \varphi=0.013 \mathrm{~mA} / \mathrm{sm}^{2}$ degree and $\mathrm{dP} / \mathrm{d} \varphi=5.1 \times 10^{-3} \mathrm{~mW} / \mathrm{sm}^{2}$ degree respectively, in case of the SSC. If the angular coefficient of the photoelectric parameters is $\theta_{n}$ for NISC and $\theta_{s}$ for SSC, the approximate relationship between them is as shown in equation (17).

$$
\theta_{n} \approx 2 \theta_{s}
$$

In the present paper, the short-circuit current has been changed to $11 \%$ for SSC and 10\% for NISC in the range of
0-60 degrees. However, when Sharma modelled a siliconbased solar cell using PC1D software, the short-circuit current was changed to $1.7 \%$ (Sharma 2019). This is because Sharma considered the frontal surface of the simple solar cell to be textured. A textured frontal surface improves the dependence of the photoelectric parameters of the solar cells on the AOI.

In 2013, Janakeeraman investigated the effect of AOI on the photoelectric parameters of photovoltaic modules. In his study, the relative short-circuit current of crystalline silicon solar module decreased by 1.7 times in the range of 0-60 degrees. Relative error measurement was less than one percentage. If the light intensity which falls perpendicular on the surface of the photovoltaic module is $1000 \mathrm{~W} / \mathrm{m}^{2}$, it will be $600 \mathrm{~W} / \mathrm{m}^{2}$ at 60 degree of AOI. (Janakeeraman 2013). In this paper, all results can be understood by changing the light intensity.

In our study, the output power of NISC and SSC drops sharply between 60 and 70 degrees. The power change rate varied for both NIS and SSC after 60 degree. In an experiment conducted by Matthieu, it was found that the power change of solar cells covered with different optical layers also varies after 60 degree (Matthieu et al. 2014). This means that the nature of the effect of nanoparticles on the optical properties of the solar cell is similar to that of the optical layers.

Since short-circuit current is linear up to 60 degree, the device can be made to measure AOI from NISC. Then it will be twice as sensitive as the sensors currently in production.

$$
\eta=\kappa \eta_{0}
$$

Equation 18 shows the relationship between the efficiency of SSC no and the efficiency of NISC $\eta$. The proportionality coefficient between the efficiency of the thin SSC and NISC developed in this scientific work was found to be $k=2.15$. Today, the maximum efficiency of simple silicon-based solar cells is $24.6 \%$ (Wilson et al 2020). So, if platinum nanoparticles are added to solar cells, their efficiency can reach $52.89 \%$.

\section{Conclusion}

In order that the efficiency of NISC relative to the efficiency of SSC is doubled, platinum nanoparticles should be arranged as follows: radius to be $15 \mathrm{~nm}$, to be inserted in $\mathrm{n}$ field of Silicon solar cell, distance between neighboring nanoparticles to be $100 \mathrm{~nm}$. However, the dependence of the photoelectric parameters of NISC on the AOI is similar to that of SSC. Platinum nanoparticles did not affect the function of each of the photoelectric parameters, with regard to their dependence on the AOI. This can lead to two conclusions. First, if nanoparticles absorb infrared light and emit visible light, then the angle of emitted light corresponds to the AOI. Second, if a nanoparticle emits extra electrons when it absorbs light, the output concentration of the electrons changes according to the AOI. This is because of the intensity of light that falls on the nanoparticle changes according to the AOI. In the solar cells which have metal nanoparticles inserted in the $\mathrm{n}$ field, the above two events can occur simultaneously. Therefore, it is clear from these results that the above conclusions do not simultaneously contradict each other. 
Citation: Gulomov, J., Aliev, R., Mirzaalimov, A., Mirzaalimov, N., Kakhkhorov, J., Rashidov, B., Temirov, S.(2021) Studying the Effect of Light Incidence Angle on Photoelectric Parameters of Solar Cells by Simulation. Int. Journal of Renewable Energy Development, 10(4),731-736, doi: 10.14170/ijred.2021.36277

P a g e $\mid 736$

\section{Acknowledgement}

The authors want to thank the staff of the Renewable Energy Sources Laboratory at Andijan State University for their close assistance in writing this article.

\section{Nomenclature and abbreviations}

$\begin{array}{ll}\mathrm{J}_{\mathrm{sc}} & \text { short circuit current density }\left[\mathrm{mA} / \mathrm{sm}^{2}\right] \\ \mathrm{U}_{\mathrm{oc}} & \text { open circuit voltage }[\mathrm{V}] \\ \mathrm{FF} & \text { Fill factor } \\ \mathrm{P}_{\mathrm{mm}} & \text { Maximum power point }\left[\mathrm{mW} / \mathrm{sm}^{2}\right] \\ \mathrm{r} & \text { Radius of nanoparticles } \\ \varphi & \text { angle of incident light [degree] } \\ \text { NISC } & \text { Nanoparticles included solar cell } \\ \text { SSC } & \text { Simple solar cell } \\ \text { TCAD } & \text { Technology computer aided design } \\ \text { TCL } & \text { Tool command language } \\ \text { SDE } & \text { Structure device editor } \\ \text { SDevice } & \text { Sentaurus device } \\ \text { SVisual } & \text { Sentaurus visual } \\ \text { SWB } & \text { Sentaurus workbench } \\ \text { AM } & \text { Air mass } \\ \text { AOI } & \text { Angle of incidence }\end{array}$

\section{References}

Atwater, H. and Polman, A. (2010) Plasmonics for improved photovoltaic devices, Nat. Mater., 9(3), 205-213.

Aliev, R., Gulomov, J., Abduvohidov, M. Aliev, S., Ziyoitdinov, Z., and Yuldasheva, Z. (2020) Stimulation of Photoactive Absorption of Sunlight in Thin Layers of Silicon Structures by Metal Nanoparticles. Appl. Sol. Energy 56, 364-370; https://doi.org/10.3103/S0003701X20050035

Benli, H. (2013). Potential of renewable energy in electrical energy production and sustainable energy development of Turkey: Performance and policies. Renewable Energy, 50, 3346.

Burgelman M, Nollet P, Degrave S. (2000) Modelling polycrystalline semiconductor solar cells. Thin Solid Films; 361-362, 527-532.

Gulomov, J., Aliev, R., Abduvoxidov, M., Mirzaalimov, A., Mirzaalimov, N. (2020). Exploring optical properties of solar cells by programming and modeling. Global Journal of Engineering and Technology Advances, 5(1), 032-038; doi.org/10.30574/gjeta.2020.5.1.0080

Gulomov, J., Aliev, R., Nasirov, M., and Ziyoitdinov, J. (2020). Modeling metal nanoparticles influence to properties of silicon solar cells, Int. J. of Adv. Res. 8(Nov), 336-345; doi.org/10.21474/IJAR01/12015

Janakeeraman, S.V. (2013). Angle of incidence and power degradation analysis of photovoltaic modules. Master thesis, Arizona state university.
Klimov, V.V. (2009) Nanoplazmonika (Nanoplasmonics), Moscow: Fizmatlit.

Kumaravelu, G. Alkaisi, M.M. and Bittar, A. (2002) Surface texturing for silicon solar cells using reactive ion etching technique, Conference Record of the Twenty-Ninth IEEE Photovoltaic Specialists Conference., New Orleans, LA, USA, 258-261; doi: 10.1109/PVSC.2002.1190507.

Matthieu, E., Heiko S., Ingrid H., Ulrich, E. (2014). The impact of angular dependent loss measurement on PV module energy yield prediction. 29th European PV solar energy conference and exhibition, Amsterdam, The Netherlands.

Yang, M., Fu, Z., Lin, F., and Zhu, X. (2011) Incident angle dependence of absorption enhancement in plasmonic solar cells. Opt. Express 19, A763-A771.

Aliev, R., Abduvoxidov, M., Mirzaalimov, N., and Gulomov., J. (2020). Kremniy asosli quyosh elementlarida rekombinatsiya va generatsiya jarayoni. Science and Education, 1(2), 230235. doi: 10.24412/2181-0842-2020-2-230-235

Solanki, C.S. and Singh, H.K., (2017) Anti-reflection and light trapping in c-Si solar cells, Green Energy and Technology, Singapore: Springer Nature,. https://doi.org/10.1007/978-98110-4771-8

Saga, T. (2010) Advances in crystalline silicon solar cell technology for industrial mass production. NPG Asia Mater 2, 96-102. https://doi.org/10.1038/asiamat.2010.82

Schuller, J. A., Barnard, E. S., Cai, W., Jun, Y. C., White, J. S., \& Brongersma, M. L. (2010). Plasmonics for extreme light concentration and manipulation. Nature materials, 9(3), 193204. https://doi.org/10.1038/nmat2630

Sentaurus device user guide, version O-2018.06, June 2018.

Sentaurus structure editor user guide, version O-2018.06, June 2018.

Sentaurus visual user guide, version O-2018.06, June 2018.

Sentaurus workbench user guide, version O-2018.06, June 2018.

Seshan, C. (2010). Cell efficiency dependence on solar incidence angle. 35th IEEE Photovoltaic Specialists Conference. d10.1109/pvsc. 2010.5616340

Sharma, R. (2019) Effect of obliquity of incident light on the performance of silicon solar cells. Heliyon vol. 5,.doi:10.1016/j.heliyon.2019.e01965

Shockley, W., and Queisser, H.J. (1961). Detailed Balance Limit of Efficiency of p-n Junction Solar Cells. Journal of Applied Physics, 32(3), 510-519; doi.org/10.1063/1.1736034

Sonnichsen, C. (2001) Plasmons in metal nanostructures, $\mathrm{PhD}$ thesis, Ludwig-Maximilians-University of Munich

Sarkar, P., Manna, A., Panda, S., Maji, B., \& Mukhopadhyay, A. K. (2018). Effect of nanoparticle size to improvement in absorption in Plasmonic solar cell. Materials Today: Proceedings, 5(10), 21225-21231. doi:10.1016/j.matpr.2018.06.522

Wilson, G.M., Al-Jassim, M., Metzger, W.K., Glunz, S.W., Verlinden, P., Xiong, G, Mansfield, L.M., Stanbery, B.J., Zhu, K., Yan, Y. (2020). The 2020 photovoltaic technologies roadmap. Journal of Physics D: Applied Physics, 53, 493001; doi.org/10.1088/1361-6463/ab9c6a 